\title{
Block Polymers for DSA (Directed Self Assembly) using Anionic Polymer Coupling Technology and Microreactor Technology
}

\author{
Youki Kou and Hisakazu Tanaka* \\ $R$ \& D Management Unit, DIC Corporation, Takaishi, Osaka 592-0001, Japan \\ *hisakazu-tanaka@mb.dic.co.jp
}

\begin{abstract}
Block polymers for DSA were prepared using anionic polymer coupling technology and microreactor technology. The effect of the molecular weight on the coupling was investigated. High molecular weight (over 50,000) homo polymers with narrow PDI were prepared in the microreactor. High molecular weight block polymer with narrow PDI was successfully prepared. by coupling of the functionalized PMMA with 1,1-diphenylethylene capped PSt $(75,900)$.
\end{abstract}

Keywords: DSA, Block polymer, Coupling, Microreactor

\section{Introduction}

Directed self-assembly (DSA) is expected to be one of the technologies for the narrowing of semiconductor patterns [1-6]. For DSA, block copolymers with high molecular weight and narrow molecular weight distribution are required $[7,8]$. Living anionic polymerization technology is usually used to prepare these kinds of polymers. However, the precise control of the molecular weight by living anionic polymerization in batch reactor systems is sometimes difficult due to the influence of water, oxygen and other impurities even in very low amounts. For the preparation of block polymers with high molecular weights, the influence of impurities must be taken into even larger consideration. In this study, the anionic polymer coupling technology was developed in order to solve these problems. Polystyrene- $b$-poly(methyl methacrylate) (PSt- $b$-PMMA) block copolymers with high molecular weight were prepared by the anionic coupling of two homopolymers. The polymerization of each homopolymer was precisely controlled by synthesis in a flow microreactor followed by coupling of these two homopolymers, block polymers with targeted molecular weight were successfully prepared.

Scheme 1 shows the synthesis route for the block polymer of PSt- $b$-PMMA. First PMMA was prepared by living anionic polymerization in the microreactor initiated by $n$-butyllithium (n-BuLi) and the functionalized 1,1-diphenylethylene (labeled 1 in Scheme 1). Then bromotrimethylsilane $\left(\mathrm{Me}_{3} \mathrm{SiBr}\right)$ was reacted in order to obtain benzyl bromide ( $\mathrm{BnBr}$ )-functionalized PMMA, allowing for the $\mathrm{BnBr}$ group to further react with polymer anions. (labeled 1 in Scheme 1). PSt was prepared by living anionic polymerization in another microreactor initiated by $n$-butyllithium (n-BuLi). The anionic end group of PSt was capped by 1,1 diphenylethylene in the same microreactor (labeled 2 in Scheme 1). Finally, polystyrene- $b$-poly (methyl metacrylate) block copolymer was prepared by the coupling of benzyl bromide (BnBr)-functionalized PMMA with 1,1-diphenylethylene capped PSt anion (labeled 3 in Scheme 1). Block polymer preparation by this coupling method has already been shown in the literature [9], however, the result was limited between two low molecular weight polymers. The method using microreactor has also been shown $[10,11]$ for the preparation of block copolymers by sequential monomer addition. The preparation of high molecular weight block polymer over $50,000 \mathrm{Da}$ is generally thought to be difficult by the coupling method. The concentration of the reacting end group becomes too low to react each other when the molecular weight of polymers becomes higher. In this study, the effect of the molecular weight of PMMA on the preparation by 
1. Preparation of functionalized PMMA

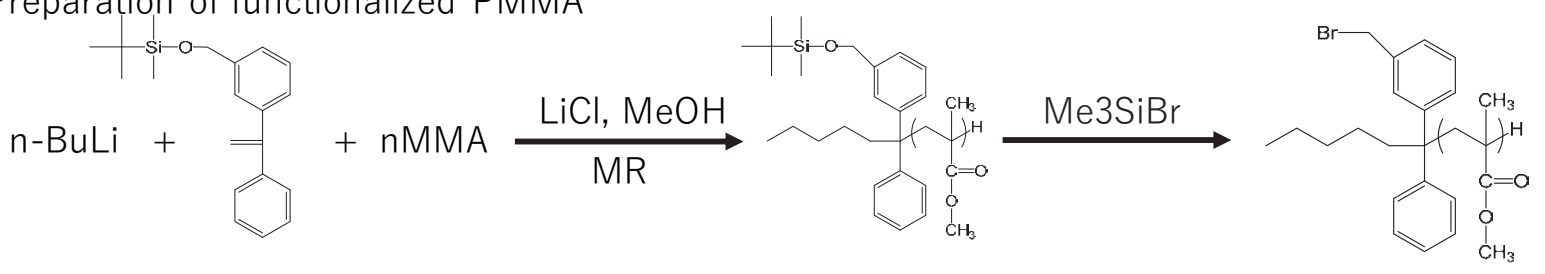

2. Preparation of PSt capped with 1,1-diphenylethylene (DPE)

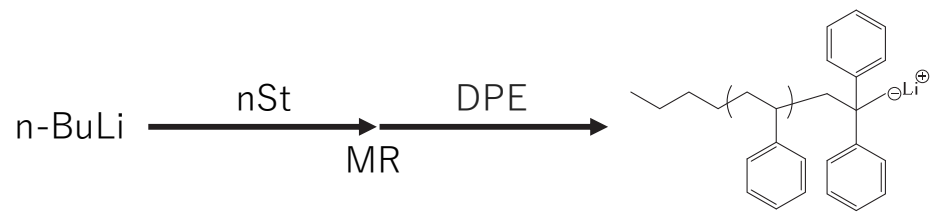

3. Coupling of benzyl bromide (BnBr)-functionalized PMMA with 1,1-diphenylethylene capped PSt

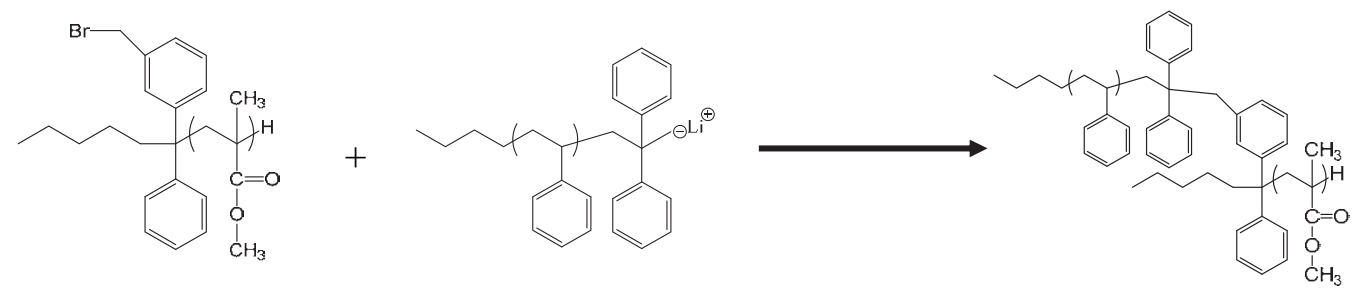

Scheme 1. Route of polystyrene- $b$-poly(methyl methacrylate) block copolymer.

the coupling method was investigated.

\section{Experimental}

\subsection{Materials}

The functionalized 1,1-diphenylethylene [1,1bis(3-tert-butyldimethylsilyloxymethylphenyl)ethylene] was synthesized by the method in the literature [12]. For all other chemicals (monomers, solvents, $\mathrm{n}-\mathrm{BuLi}, \mathrm{LiCl}$ ), industrial grade was used.

\subsection{Microreactor}

A microreactor for the preparation of homopolymers consists of micromixers and tubes. Each solution was placed under a positive pressure of argon gas and was flowed into the microreactor using HPLC pumps (GL Science Inc.) and was mixed in the micromixer. Polymerization occurred in the tubes connected to the micro mixer. Polymerization temperature was controlled by immersing the tube in a cooled bath.

\subsection{Measurements}

GPC, GC and NMR were used to analyze the results.

\section{Results and discussion}

3.1. Preparation of functionalized PMMA in the microreactor

Scheme 2 shows the microreactor system used for the preparation of the functionalized PMMA and the results are presented in Table 1 . By immersing the microreactor in a $-70{ }^{\circ} \mathrm{C}$ bath, high molecular weight

PMMA homopolymers over 50,000 Da with narrow PDI could be obtained with measured molecular weights and calculated molecular weights being very close. Figure 1 shows the GPC traces and no satellite peaks could be seen.

\subsection{Conversion to benzyl bromide functional group}

Table 2 shows the effect of the molecular weight on the conversion to benzyl bromide group to form the (BnBr)-functionalized PMMA. As the molecular weight increased, the rate significantly decreased, however the conversion could be improved to $94 \%$ by extending the reaction time and increasing the reactant concentrations even in the case of PMMA with a $M n$ of 45,000 Da. PMMA over 50,000 is likely to be possible to be converted to $(\mathrm{BnBr})$ functionalized PMMA efficiently. 


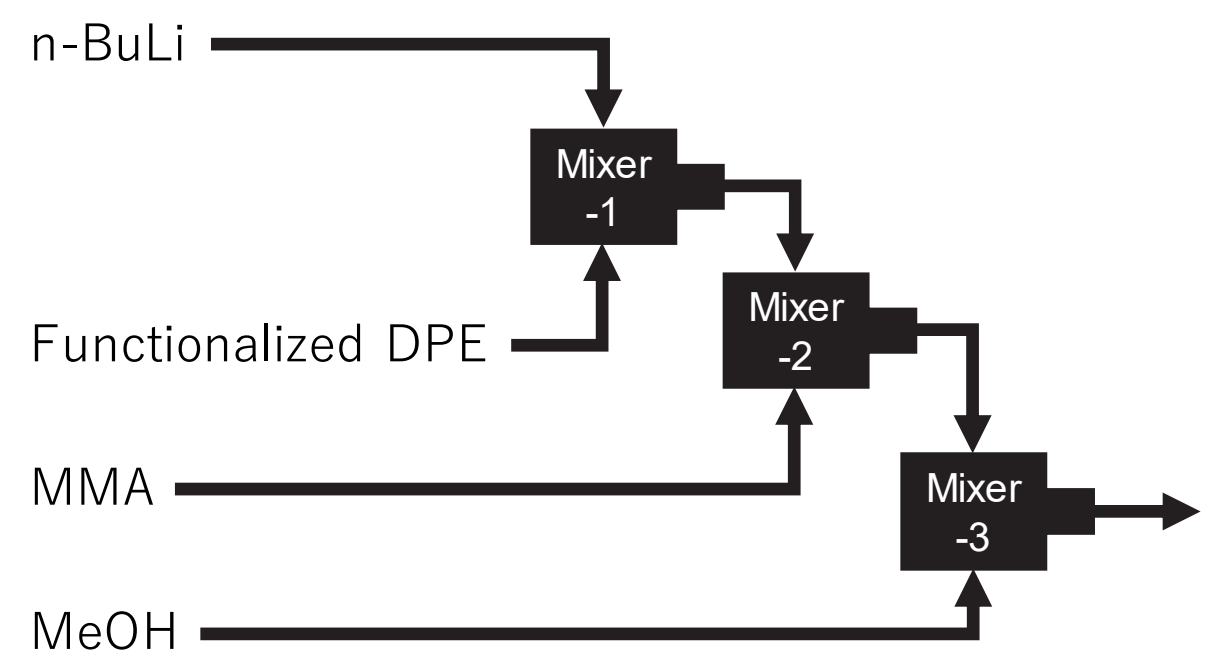

Scheme 2. Microreactor system for PMMA.

Table 1. Results of the preparation of the functionalized PMMA.

\begin{tabular}{ccccccc}
\hline & \multicolumn{4}{c}{ Molecular Weight from GPC } & & \multicolumn{2}{c}{$\begin{array}{l}\text { Reaction } \\
\text { rate (\%) }\end{array}$} \\
& Calculated & $M n$ & $M w$ & $M w / M n$ & Top & MMA \\
1 & 60,100 & 55,600 & 58,200 & 1.048 & 55,600 & 99.2 \\
2 & 79,900 & 81,300 & 85,400 & 1.050 & 82,900 & 97.7 \\
\hline
\end{tabular}
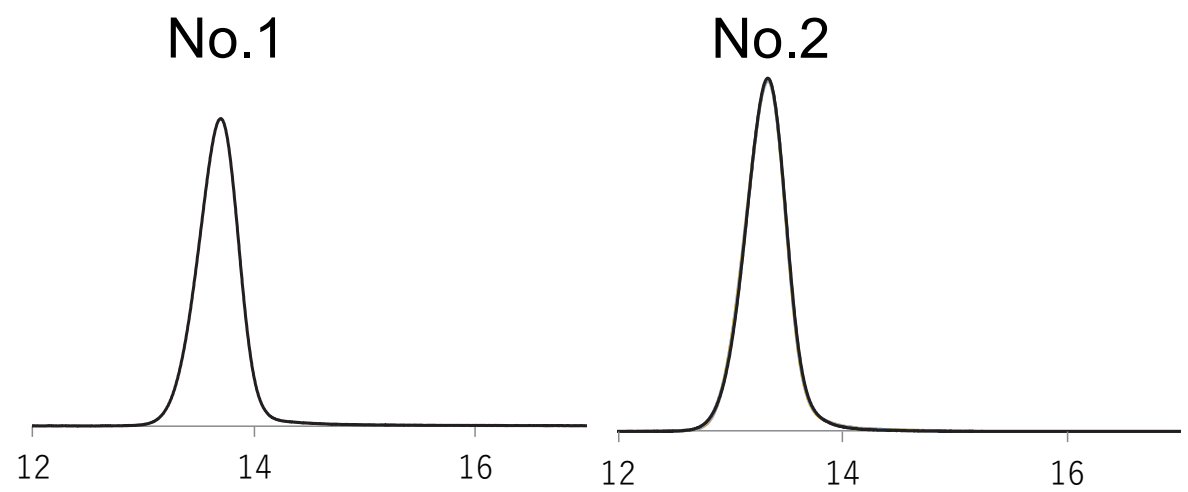

Fig. 1. GPC result of PMMA preparation.

Table 2. The effect of the molecular weight on the conversion to benzyl bromide group.

\begin{tabular}{ccccccc}
\hline & Mn of PMMA & $\begin{array}{c}{[-\mathrm{Si}]} \\
/ \mathrm{M}\end{array}$ & $\begin{array}{c}\text { [TMS-Br] } \\
/ \mathrm{M}\end{array}$ & $\begin{array}{c}\text { Ratio of } \\
\mathrm{Br} / \mathrm{Si}\end{array}$ & $\begin{array}{c}\text { Conversion Conversion } \\
\text { after 24h } \\
/ \%\end{array}$ & $\begin{array}{c}\text { after 140h } \\
/ \%\end{array}$ \\
\hline 1 & 6500 & 0.0154 & 3.07 & 199 & 99.2 & - \\
2 & 18000 & 0.0056 & 1.11 & 198 & 98.8 & - \\
3 & 45000 & 0.0022 & 0.44 & 200 & 39.6 & 61.7 \\
4 & 45000 & 0.0056 & 1.2 & 214 & 73.1 & 94.1 \\
\hline
\end{tabular}



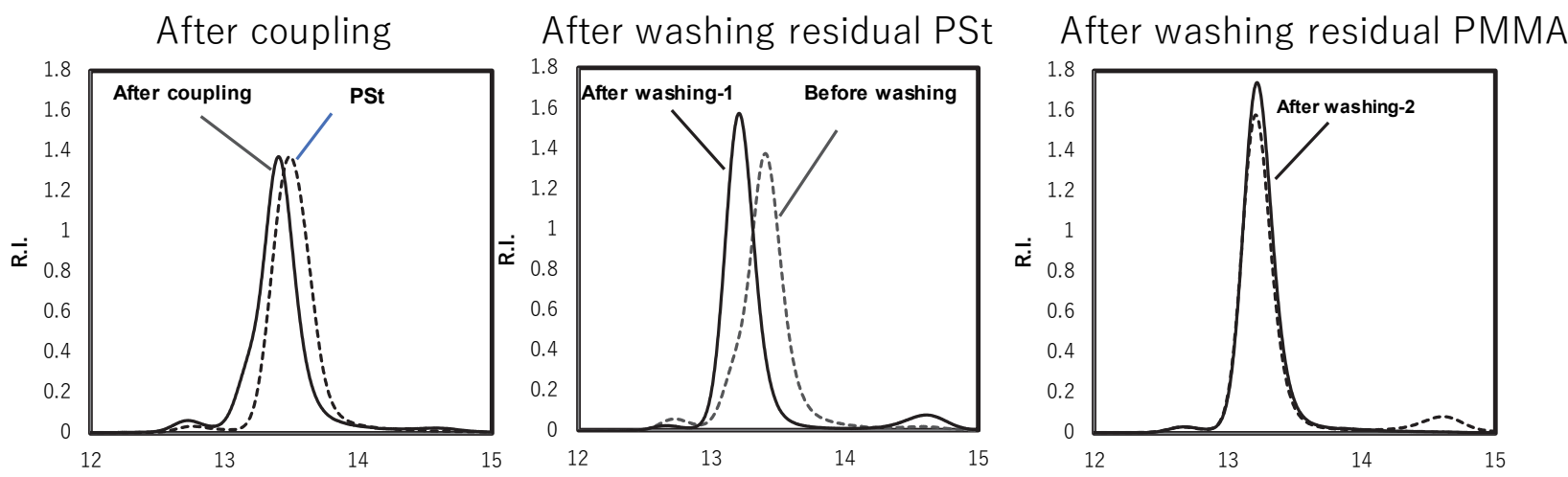

Fig. 3. Result of coupling of benzyl bromide (BnBr)-functionalized PMMA with 1,1-diphenylethylene capped PSt.

\subsection{Preparation of PSt in the microreactor}

Scheme 3 shows the microreactor system for the preparation of PSt capped with 1,1-diphenylethylene. Figure 2 shows both batch and microreactor results. In the batch system, PSt main peak was narrower though a small satellite peak was seen. In the case of microreactor, main peak molecular weight distribution was wider, but no satellite peaks were seen. The satellite peak is likely to be caused by radical coupling of two PSt end groups after PSt polymerization. By quick capping by 1,1diphenylethylene in the micromixer, any satellite polymer is not likely to be made in the case of microreactor.

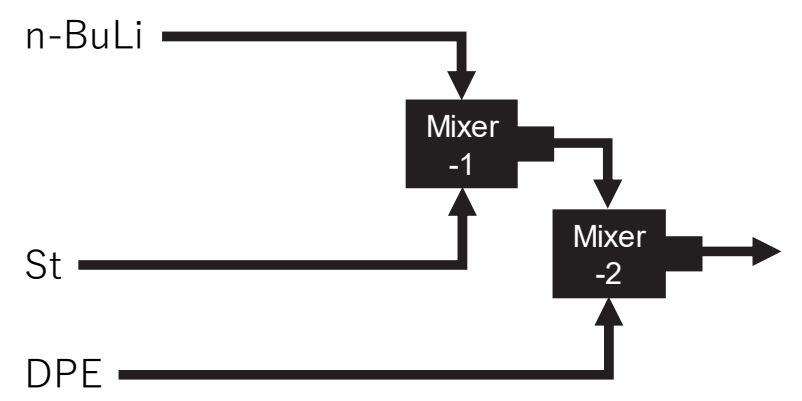

Scheme 3. Microreactor system for PSt.
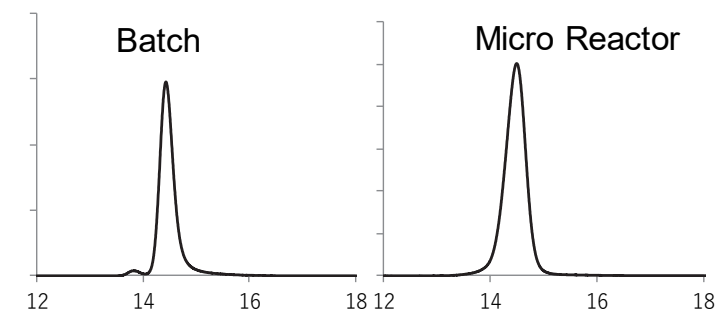

Caluculated $\mathrm{Mn} \mathrm{Mw} \mathrm{Mw} / \mathrm{Mn}$ $\begin{array}{llll}23,000 & 23,400 \quad 24,200 & 1.034\end{array}$

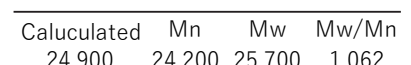
$\begin{array}{llll}24,900 \quad 24,200 & 25,700 & 1.062\end{array}$

Fig. 2. Batch and microreactor PSt preparation results.
3.4. Coupling of benzyl bromide (BnBr)functionalized PMMA with 1,1-diphenylethylene capped PSt

The results of coupling of benzyl bromide (BnBr)-functionalized PMMA with 1,1diphenylethylene capped PSt can be seen in Fig. 3. In this experiment, PSt was prepared in the batch system. Small satellite peak is seen in the GPC curve. The functionalized PMMA was prepared in the microreactor and PMMA with $60 \%$ conversion to benzyl bromide functional group was used. As a result, washing of both residual PSt homopolymer and PMMA homopolymer was needed after coupling. In Fig. 3, Mn=92,400 block polymer with narrow $\mathrm{PDI}=1.03$ is successfully prepared by coupling of the functionalized PMMA $(M \mathrm{w}=18,000)$ with $1,1-$ diphenylethylene capped PSt $(75,900)$. This block polymer showed cylindrical phase separation as expected for this ratio of PMMA and PSt as seen in Fig. 4.

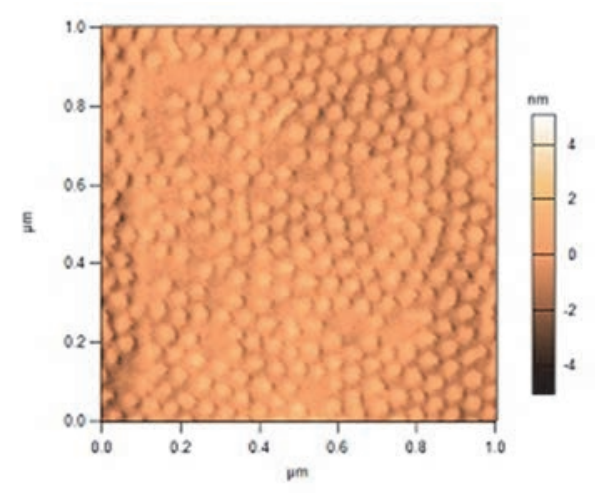

Fig. 4. Expected phase separation by the coupling block polymer. This result was obtained by using block polymer with same range of molecular weight by common living anionic polymerization. 


\section{Conclusion}

The preparation of high molecular weight block polymer with narrow PDI was successfully prepared using the coupling technology and microreactor technology.

Recently, the high- $\chi$ block polymers are required for the narrower semiconductor pattern $(<10 \mathrm{~nm})$ [2$6,13]$. The block polymerization of the monomers for high- $\chi$ is sometimes very difficult, because the molecular weight of monomers is too large in many cases and the purification by distillation cannot be applied. However, the influence of the impurities on the polymerization of homo polymer is considered to be small. The anionic coupling method shown in this study is likely to be easily applied for the preparation of the high- $\chi$ block polymers.

\section{Acknowledgement}

In this research, we have received much advice from Associate Professor Tomoya Higashihara in Yamagata University.

\section{References}

1. Y. Matsushita, J. Suzuki, Y. Izumi, K. Matsuoka, S. Takahashi, Y. Aoyama, T. Mihira, and A. Takano, J. Chem. Phys., 133 (2010) 194901.

2. H.-C. Kim, S.-M. Park, and W. D. Hinsberg, Chem. Rev., 110 (2010)146.

3. C. M. Bates, M. J. Maher, D. W. Janes, C. J. Ellison, and C. G. Willson, Macromolecules, 47
(2014) 2 .

4. L. Wan, R. Ruiz, H. Gao, K. C. Patel, T. R. Albrecht, J. Yin, J. Kim, Y. Cao, and G. Lin, ACS Nano, 7 (2015) 7506.

5. C. Wang, X. Li, and H. Deng, ACS Macro Lett., 8 (2019) 368.

6. T. Isono, N. Kawakami, K. Watanabe, K. Yoshida, I. Otsuka, H. Mamiya, H. Ito, T. Yamamoto, K. Tajima, R. Borsali, and T. Satoh, Polym. Chem., 10 (2019) 1119.

7. T. Yamaguchi and A. Fujiwara, 28th International Microprocesses and Nanotechnology Conference (MNC), 2015.

8. T. Kosaka, R. Matsuki, Y. Kawaguchi, and R. Ogaki, Proc. SPIE, 10960 (2019) 1096011.

9. R. Goseki, A. Hirao, M. Kajimoto, and T. Hayakawa, ACS Macro Lett., 2 (2013) 625.

10. H. Tanaka, N. Oe, Y. Uemura, M. Kimura, and F. Ishiyama, Japan Patent 6225438.

11. J.-S. Kim, J.-O. Kweon, J.-H. Lee, and S.-T. Noa, Macromol. Res., 23 (2015) 100.

12. T. Higashihara, Ph. D. thesis, Tokyo Institute of Technology (2005).

13. C. Navarro, C. Nicolet, F Ariura, X. Chevalier, K. Xu, M. A. Hockey, M. Mumtaz, G. Fleury, G. Hadziioannou, A. Legrain, M. Zelsmann, A. Gharbi, R. Tiron, L. Pain, L. Evangelio, M. FRegúlez, F. P.-Murano, and I. Cayrefourcq, J. Photopolym. Sci. Technol., 30 (2017) 69. 